\title{
ARTICLE \\ Effect of Phenolic Components of Earth Apple (Helianthus Tuberosus) in the Inhibiting of Oxidation and Extension the Shelf-life of Vegetable Oils
}

\author{
Adnan W. H. Al-Mudhafr ${ }^{*} \quad$ Wafaa A. Raheem ${ }^{2}$ \\ 1.Department of Food Science, University of Kufa, Iraq \\ 2.Faculty of Administration and Economics, Al-Imamja.Afar alSadeq
}

\begin{tabular}{|c|c|}
\hline ARTICLE INFO & ABSTRACT \\
\hline Article history & \multirow{12}{*}{$\begin{array}{l}\text { Earth Apple (Helianthus tuberosus) phenolic compounds were extracted } \\
\text { using two methods ethanol extraction ( } 98 \text { percent ethanol for } 24 \text { hours } \\
\text { at room temperature) and water extraction (distilled water for } 24 \text { hours } \\
\text { at room temperature). To measure the sum of phenols in the extract, the } \\
\text { Folin-Ciocateu method was used. The alcohol extract gave a higher phe- } \\
\text { nol content of } 58.29 \mathrm{mg} / \mathrm{g} \text { (gallic acid), while the alcoholic extract had } \\
\text { flavonoids } 26.63 \mathrm{mg} / \mathrm{g} \text { (gallic acid). Water extract was phenols content of } \\
42.62 \mathrm{mg} / \mathrm{g} \text { (gallic acid) while the alcoholic extract had flavonoids } 11.23 \\
\mathrm{mg} / \mathrm{g} \text { (gallic acid). The alcoholic extract from Earth Apple gave the high- } \\
\text { est antioxidant effect at } 88.32 \% \text {, while the water extract was } 77.43 \% \text {. The } \\
\text { inhibitory effect of the added Earth Apple extract oil to inhibit oxidation, } \\
\text { remove concentrations ( } 0.1,0.15,0.2 \text { percent) of Palm Oil and Sunflower } \\
\text { oil as it exceeded the reduction of peroxide values during the reservoir } \\
\text { periods }(15,30,45,60 \text { days). }\end{array}$} \\
\hline Received: 30 March 2021 & \\
\hline Accented: 19 April 2021 & \\
\hline & \\
\hline Published Online: 15 May 2021 & \\
\hline Keywords: & \\
\hline Phenolic compounds & \\
\hline & \\
\hline Earth apple & \\
\hline Antioxidant activity & \\
\hline Palm oil & \\
\hline Sunflower oil & \\
\hline
\end{tabular}

\section{Introduction}

The Earth Apple is one of the spring vegetable crops belonging to the tent family (Helianthus tuberosus). Family asteraceae of perennial vegetable crops, but are re-grown annually as the total vegetative dies annually during Winter to give new growths during the spring. The part that is eaten is tubers that are made up at the end of the legs. The rhizomes are irregular and have protrusions which are the eyes that contain the buds and are eaten It is cooked or used in pickling and is rich in Inulin, which is used in the industry to obtain Sugar inulin also contain phenolic substances acting as antioxidants ${ }^{[35,2]}$. The Earth Apple is one of the most important vegetables in the world. Its biologically active ingredients may be beneficial to a large number of consumers. It is rich in healthy antioxidants such as carotenoids, hydrophilic substances such as phenolic compounds $[3,4,5]$. The Earth Apple was first used for medical purposes and was gradually used as food ${ }^{[6]}$. Researchers explained Earth Apple contains antioxidants, especially beta-carotene, It has beneficial health effects such as anti-cancer and antioxidants, and in enhancing immunity, as well as the activity of some carotenoids. Earth Apple is rich in antioxidants, whether carotenoids or hydrophilic phenols ${ }^{[8,9]}$. Although the content of carotenoids varies greatly between the structures of the Earth Apple ${ }^{[10]}$. The oils extracted from plants play an important role in the industry. Among the known

*Corresponding Author:

Adnan W. H. Al-Mudhafr,

Department of Food Science, University of Kufa, Iraq;

Email: adnan.almudhafar@uokufa.edu.iq 
species of these compounds, tannins, which were used in tanning, ink manufacturing, and phenolic compounds in the manufacture of colored materials. Phenolic compounds are known as low molecular weight compounds containing an aromatic ring with one or more hydroxyl groups ${ }^{[1]}$. Phenolic compounds are part of plant compounds with a long history in industries such as tanning skin, wine and inks, as well as their important role in human health ${ }^{[12]}$. Inedible and edible food crops contain multiple phenols with multiple applications in the food, pharmaceutical and cosmetic industries ${ }^{[13]}$. Phenolic compounds, they join oxidation processes by breaking down the chain of active reactions, called "primary oxidation," or by eliminating free radicals, or "secondary oxidation According to" ${ }^{[7,14]}$. Fatty oxidation occurs in food oils at various stages of processing, storage, purchase, and even use ${ }^{[15]}$. The primary source of palm oil is the oil palm (Elaeis guineensis). Phenolic compounds, terpenes, and sterols are the most common phytochemicals found in palms ${ }^{[16]}$. Sunflower (Helianthus annuus L.) cultivation has increased dramatically in recent years, owing to the high quality of its oil, which is suitable for human consumption ${ }^{[17]}$. Unsaturated fatty acids (linoleic 56 percent, oleic 30 percent, linolenic 0.7 percent). It also has a protein value of 37 percent clopulin, 51 percent clotillin, and 7 percent insoluble oils. Palm oil also contains a number of amino acids, Tocopherol (vitamin E), beta-sitosterol , and phytine, both of which are high in vitamin E (tocopherol) ${ }^{[18]}$. Palm's high content of unsaturated fatty acids, such as linoleic acid, helps to lower LDL, which decreases cholesterol in the blood and prevents atherosclerosis and blood vessel disease. It also induces a decrease in blood pressure. Cholesterol-linked diseases were once common ${ }^{[19]}$. Triglycerides, or esters of triglyceride fatty acid, are found naturally in oils and fats. Peroxidase is a measure of the oxidative oxidation of oils, and therefore of the nature of the products that contain these oils ${ }^{[20,21]}$.

\section{Materials and Methods}

\subsection{Preparation of Plant Extracts}

\subsubsection{Alcoholic Extraction}

I created alcoholic extracts utilizing method ${ }^{[22]}$, weighing $100 \mathrm{~g}$ of each sample and adding $500 \mathrm{ml}$ of 98 percent ethyl alcohol, mixing well, and leaving for 24 hours at room temperature $25-30^{\circ} \mathrm{C}$. The extract was then filtered using Whatman No.1 filter paper. The concentrated filtrate was then filtered using a Vacuum Evaporator rotary evaporator at a temperature of $40^{\circ} \mathrm{C}$, and the packaging was sealed and sealed in the refrigerator before use, and the concentrated filtrate was left at the laboratory temperature until a concentrated sticky material was collected.

\subsubsection{Aqueous Extraction}

Prepare the water extracts ${ }^{[23]}$, weighing $100 \mathrm{~g}$ of each sample with $500 \mathrm{ml}$ distilled boiling water and mixing for 24 hours and 30 minutes on a magnetic mixer. Then, with the Buchner funnel, sprinkle through the Whatman No.1 filter paper with discharge and concentrate the rotary vacuum evaporator at $40{ }^{\circ} \mathrm{C}$, it is mounted at laboratory temperature $30-25{ }^{\circ} \mathrm{C}$, put in dark containers, and held in refrigerator until use.

\subsection{Estimate of Total Phenols}

By dissolving $1 \mathrm{~g}$ of plant extracts in $46 \mathrm{~mL}$ of distilled water and $1 \mathrm{~mL}$ of the Folin-Ciocalteu reagent, the value of phenols in the water and alcohol extracts of the plants was calculated The ingredients had been thoroughly combined. $3 \mathrm{~mL}$ sodium carbonate (2 percent) $\mathrm{Na}_{2} \mathrm{CO}_{3}$, shake for 2 hours, then test absorption at $760 \mathrm{~nm}$. The amount of phenols in the extracts was determined using a standard solution of Gallic acid at a concentration of $0-100 \mathrm{mg} / \mathrm{ml}$ and a correlation between acid concentration and absorption at a $760 \mathrm{~nm}$ wavelength. used the Folin-Ciocalteu method ${ }^{[24]}$.

\subsection{Estimate of Total Flavonoids}

The method described above ${ }^{[25]}$ Dissolving $1 \mathrm{~g}$ of plant extracts in $1.5 \mathrm{ml}$ ethyl alcohol and adding an equivalent amount of $\mathrm{AlCl}_{3}$. $6 \mathrm{H}_{2} \mathrm{O}$ concentration was used to measure the total flavonoids content in plant extracts ( 2 percent in $100 \mathrm{ml}$ methanol). The concentration of flavonoids in the extracts was determined by making a standard solution of the Rutin flavonide compound with concentrations ranging from $(0-100 \mathrm{mg} / \mathrm{ml})$ and measuring the absorption at $367 \mathrm{~nm}$ wavelength. By using the graphical relationship between acid concentration and absorption, the volume of flavonoids was assessed.

\subsection{Antioxidant Activity}

Antioxidant efficacy in alcoholic and aqueous extracts was estimated according to the method described in ${ }^{[26]}$ using the proposed linoleic acid system ${ }^{[27]}$. Preparation of a mixture consisting of $4.1 \mathrm{~mL}$ linoleic acid (2.5 percent ethanol), $4 \mathrm{~mL}$ per extract, $8 \mathrm{~mL}$ phosphate-regulated solution $0.05 \mathrm{mM}$ and $\mathrm{pH}=7$ and $3.9 \mathrm{~mL}$ distilled water, incubation at $40^{\circ} \mathrm{C}$ for 24 hours in dark-brown containers. Add $0.1 \mathrm{~mL}$ of mixture to $9.7 \mathrm{~mL}$ of ethanol (75 percent concentration) and $0.1 \mathrm{~mL}$ of ammonium thiocyanate to calculate the percentage of thiosanate oxidation (30 percent concentration). After three minutes, $0.1 \mathrm{~mL}$ chloride (20 mL molariate concentration) in 3.5 percent hydrochlo- 
ric acid, and then measuring absorbance with a $500 \mathrm{~nm}$ wavelength, the control sample was prepared in the same way as the above but with $4 \mathrm{~mL}$ ethanol instead of plant extract. Calculation rate of linoleic acid peroxides was calculated according to the following equation:

Antioxidant effectiveness $\%=100-\frac{\text { Read the absorption of the model }}{\text { Read the absorption of the control sample }} \times 100$

\subsection{Antioxidants in the Oil}

I followed the method described by Scott (1965) and then dissolving $0.02 \%$ of the industrial antioxidant BHT and phenolic extracts $0.1,0.15,0.2 \%$ in the ethyl alcohol and added to the sunflower oil and palm oil samples at 45 ${ }^{\circ} \mathrm{C}$ to equal the final concentration of antioxidant in the oil as stated ${ }^{[28]}$, then mix the mixture well and incubated the degree Heat $45^{\circ} \mathrm{C}$ and put another model of oil free of the antioxidant promised a comparison model. The antioxidant efficiency of the oil was followed for 60 days by estimating the peroxide value according to the method mentioned in ${ }^{[29]}$.

\section{Results and Discussion}

\subsection{Total Content of Phenols}

Figure 1 appears the contrasts between water and alcoholic extracts in phenolic compounds of the Earth Apple with $58.27 \mathrm{mg} / \mathrm{g}$ for the extracts and $42.62 \mathrm{mg} / \mathrm{g}$ for the water extricate. The contrast within the sum of phenolic compounds between water and alcoholic extracts is due to the nature of the partitioned compounds and the dissolvability of total solvents utilized for extracts. ${ }^{[30]}$ The control of water extracts contains little amounts of phenolic compounds compared with tall levels of alcoholic extracts due to ethanol effectiveness within the extracts of polyphenols and tannins from the plant ${ }^{[31]}$.

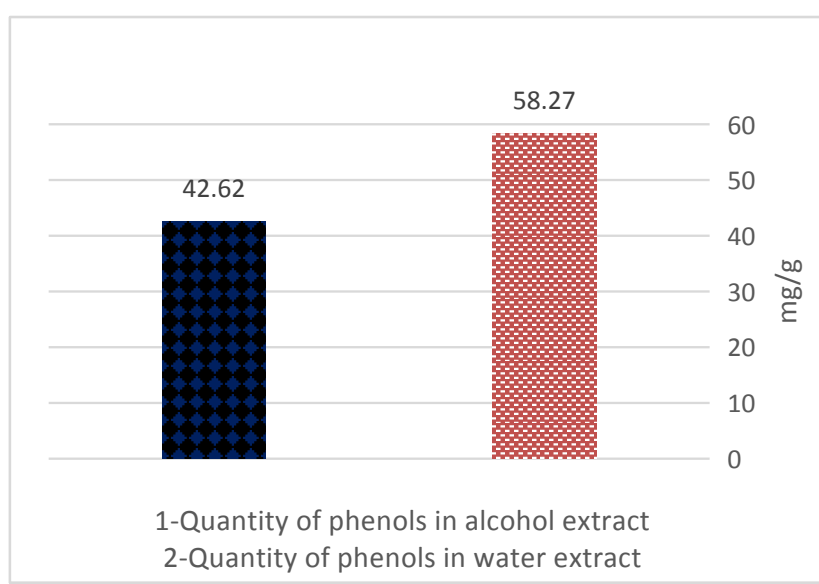

Figure 1. Total substance of phenolic compounds in Earth Apple extricate

\subsection{Total Flavonoids Content}

Figure 2 appears the sum of flavonoids in water and liquor extricate from Earth Apple extricate. The most noteworthy concentration of flavonoids within the Earth Apple extricate was $26.61 \mathrm{mg} / \mathrm{g}$, taken after by Earth Apple $(11.25 \mathrm{mg} / \mathrm{g})$. The total flavonoids in water alcohol extricate are due to the high ethanol resistance of phenolic compounds for diverse sorts of natural products compared to other solvents ${ }^{[32]}$.

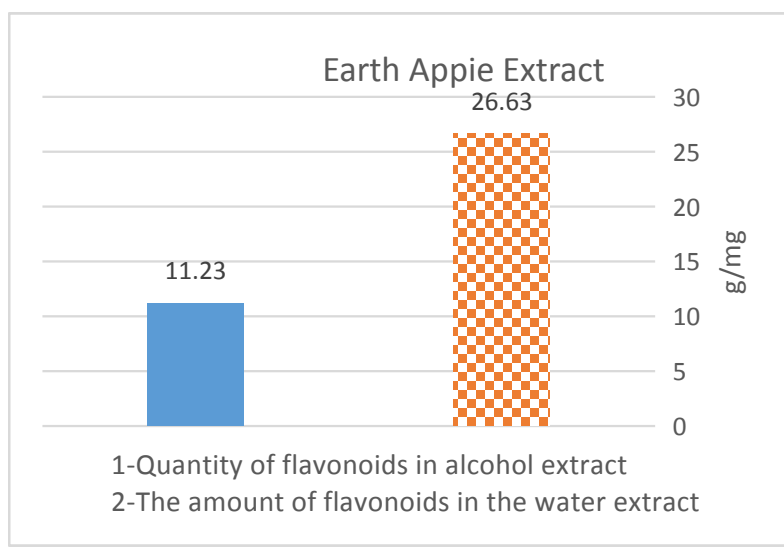

Figure 2. Total flavonoids content of Earth Apple extract

\subsection{Antioxidant Activity}

Figure 3 shows the effectiveness of antioxidants between prepared extracts, industrial antioxidants, and alcohol and water extracts. Oil extracts from the Earth Apple gave the highest antioxidant effect of $88.32 \%$ and was lower than BHT 96.21\%. The water extract of the Earth Apple gave an antioxidant effect of $77.41 \%$. The contrasts between water and alcohol extracts in antioxidant viability values may be due to the nature and concentration of phenolic compounds found in plants as well as to the sort and nature of the dissolvable ${ }^{[33,34]}$

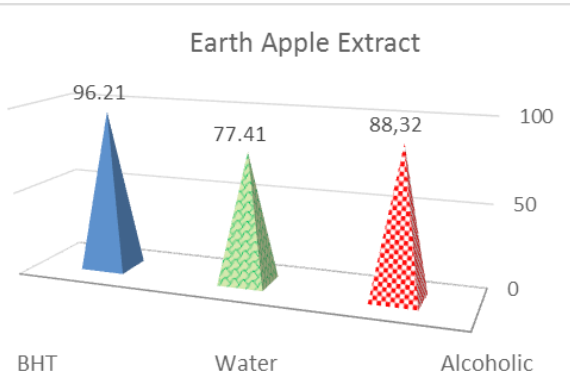

Figure 3. Antioxidant efficacy in the extract of water and alcohol.

\subsection{Obstruction of Oil Oxidation}

\subsubsection{Palm Oil}

Table 1 shows the effect of alkaline extract of pheno- 
lic substances $(\mathrm{T} 1, \mathrm{~T} 2, \mathrm{~T} 3)$ in concentrations $(0.1,0.15$, 0.2 ) as well as the T4 water extract at a concentration of $0.2 \%$ and compared with the control sample T5 (without addition) and another sample T6 added (BHT) to the values of peroxide of Palm oil stored for periods $(15,30$, $45,60)$ day and temperature of $45{ }^{\circ} \mathrm{C}$ the results showed that the T3 concentration was higher than $0.2 \%$ for the 60 day storage period of $2.81 \mathrm{Meq} / \mathrm{kg}$ oil compared to the T6 treatment using industrial antioxidants (BHT) of $3.02 \mathrm{Meq} / \mathrm{kg}$ oil if there were no significant differences at 0.1 , Compared to the control sample of $11.0 \mathrm{Meq} / \mathrm{kg}$ of olive oil for 60 days, with significant differences between the results this means that natural substances can be used instead of industrial materials to preserve oils and get better results without side effects on public health because the antioxidant mechanism inhibits oil oxidation during storage periods due to its interaction with free radicals or decomposition of peroxides or formation of complexes with metal ions ${ }^{[35]}$. Research showed that the value of peroxide in olive oil and canola oil was about 10.62.5.73 $\mathrm{Meq} / \mathrm{kg}$ oil respectively ${ }^{[36]}$.

Table 1. Effect of the Earth Apple extract Peroxide values $(\mathrm{Meq} / \mathrm{kg}$ ) for Palm Oil for different storage periods and storage grade $45^{\circ} \mathrm{C}$

$\begin{array}{cccccccc}\begin{array}{c}\text { Storage Dura- } \\ \text { tion (Day) }\end{array} & \text { T1 } & \text { T2 } & \text { T3 } & \text { T4 } & \text { T5 } & \text { T6 } & \text { Fruit } \\ 0 & 6.04 & 6.04 & 6.04 & 6.04 & 6.04 & 6.04 & -- \\ 15 & 5.42 & 5.11 & 4.83 & 4.42 & 8.04 & 3.02 & 5.14 \\ 30 & 4.11 & 3.41 & 2.83 & 3.03 & 8.04 & 3.02 & 4.07 \\ 45 & 3.42 & 3.41 & 3.04 & 4.02 & 8.42 & 3.02 & 4.22 \\ 60 & 4.42 & 3.02 & 2.81 & 3.01 & 11.00 & 3.02 & 4.54\end{array}$

(T1) $\% 0.1$ Alcoholic ( T2) $0.15 \%$ Alcoholic (T3) $0.2 \%$ Alcoholic (T4) $0.2 \%$ water (T5) Control (T6) $0.2 \%$ BHT

\subsubsection{Sun Flower Oil}

Table 2 appears the impact of Earth Apple extricate on the peroxide values of sunflower Oil for distinctive capacity periods and at $45^{\circ} \mathrm{C}$ all medications appeared an viable anti-oxidant impact of sunflower oil and essentially compared to the control test $\mathrm{T} 5$ and the mechanical antioxidant T6, comes about appear that all concentrations appeared inhibitory viability to repress oil oxidation but to shifting degrees based on concentrations antioxidant action expanded with expanded concentration. there was no noteworthy contrast between the peroxide values of the most elevated concentration and its esteem with the mechanical antioxidant, whereas there was a quick increment within the peroxide esteem of the T5 control test
18.0 Meq/kg and medications (T1, T2, T3, T4) appeared the next impact of mechanical cancer prevention agents amid the 60 day capacity period $(3.43,3.22,3.22,4.03)$ $\mathrm{Meq} / \mathrm{kg}$, whereas T6 $(4.80 \mathrm{Meq} / \mathrm{kg})$ in this respect, plant extracts have appeared tall antioxidant movement due to their capacity to restrain oxidation of fat and oils for their capacity to tie press, which is among the compounds that are characterized by compelling phenolic compounds in these plant extracts ${ }^{[37]}$.

Table 2. Effect of Earth Apple extract on peroxide values $(\mathrm{Meq} / \mathrm{kg}$ ) for Corn Oil for different storage periods and storage grade $45^{\circ} \mathrm{C}$

$\begin{array}{ccccccccc}\begin{array}{c}\text { Storage } \\ \begin{array}{c}\text { Duration } \\ \text { (Day) }\end{array}\end{array} & \text { T1 } & \text { T2 } & \text { T3 } & \text { T4 } & \text { T5 } & \text { T6 } & \\ 0 & 8.10 & 8.10 & 8.10 & 8.10 & 8.10 & 8.10 & \\ 15 & 5.41 & 4.62 & 4.21 & 5.00 & 11.03 & 3.00 & 5.54 \\ 30 & 6.02 & 4.43 & 3.60 & 3.02 & 16.04 & 3.00 & 6.01 \\ 45 & 5.02 & 4.62 & 4.40 & 3.02 & 16.05 & 3.00 & 601 \\ 60 & 3.43 & 3.22 & 3.22 & 4.03 & 18.00 & 4.80 & 6.11 \\ \text { (T1)\%0.1 Alcoholic ( T2) } 0.15 \% \text { Alcoholic (T3) } 0.2 \% \text { Alcoholic } \\ \text { (T4) 0.15\% water (T5) Control (T6) 0.2\% BHT }\end{array}$

\section{Statistical Analysis}

Complete Randomized Design (C.R.D) was used to analyze all the studied factors as statistically analyzed. These factors were tested using a least significant difference (L.S.D.) at a probability level of $0.05^{[38]}$.

\section{Conclusions}

The results showed that the quantities of phenols extracted alcoholic higher than the extraction of water from the Earth Apple, and added to different concentrations helped to an increase in stability for vegetable oils more than 60 days at a temperature of $45^{\circ} \mathrm{C}$.

\section{References}

[1] Young, A. J.; D. M. Phillip, and G. M. Lowe. (2004). Carotenoid Antioxidant Activity. Pp. 105-126. In: Krinsky, N. I.; S. T. Mayne, and H. Sies. (eds.) Carotenoids in Health and Disease. Marcel Dekker Inc., NY., USA. PP: 551.

[2] Linting, J.V., (2004). Conversion of Carotennoids to Vitamin A:New Insights on the Molecular Level. PP. 337-356. In: Krinsky, N. I.; S. T Mayne, and H. Sies. (eds.). Carotenoids in Health and Disease. Marcel Dekker Inc., NY., USA. PP: 551. 
[3] Hager T.J., Howard L.R. (2006). Processing Effects on Earth Apple Phytonutriens. Horticultural Science, 41: 74-79.

[4] Sharma K.D., Karki S., Thakur N.S., Attri S. (2012). Chemical composition, functional properties and processing of. Earth Apple J. of Food Science and Technology, 49: 22-32.

DOI: $10.1007 / \mathrm{s} 13197-01103107$.

[5] Leja M., Kaminská I., Kramer M., Maksylewicz-Kaul A., Kammerer D., Carle R., Baranski R. (2013). The Content of Phenolic Compounds and Radical Scavenging Activity Varies with Carrot Origin and Root Color. Plant Foods Human Nutrition, 68: 163-170. DOI: $10.1007 / \mathrm{s} 11130-013-0351-3$.

[6] Da Silva Dias, J. C. (2014). Nutritional and health benefits of Earth Apple and their seed extracts. Food and Nutrition Sciences, 5(22), 2147 .

[7] Augspole, I., Rackejeva, T., Kruma, Z., \& Dimins, F. (2014). Shredded carrots quality providing by treatment with Hydrogen peroxide. In 9th Baltic Conference on" Food for Consumer Well-Being" FOODBALT (pp. 150-154).

[8] Tanaka T., Shnimizu M., Moriwaki H. (2012). Cancer Chemoprevention by Carotenoids. Molecules, 17: 3202-3242.

DOI: $10.3390 /$ molecules17033202.

[9] Fiedor J., Burda K. (2014). Potential Role of Carotenoids as Antioxidants in Human Health and Disease. Nutriens, 6:466-488.

DOI: $10.3390 /$ nu6020466.

[10] Baranski, R., Allender, C., \& Klimek-Chodacka, M. (2012). Towards better tasting and more nutritious carrots: Carotenoid and sugar content variation in carrot genetic resources. Food research international, 47(2), 182-187.

[11] Halfi, Sawsan Ali Hamid (2009). Extraction, separation and diagnosis of phenolic compounds and their derivatives from vegetable sources and their use in microbes and microbial inhibitors and their application in food systems.

[12] Ramli, S. (2006). Total phenolic content and antioxidant activity of flavonoids isolated from leaves of selected citrus species. Msc. Thesis., University Putra, Malaysia.

[13] Kähkönen, M.P.; Hopia, A.I.; Vuorela, H.J.; Rauha, J.P.; Pihlaja, K.;Kujala, T.S and Heinonen, M. (1999). Antioxidant activity of plant extracts containing phenolic compounds . J. Agric. Food Chem. 1999, Vol.47, No.10,pp. 3954-3962.

[14] Ndhlala, A. R., Moyo, M., \& Van Staden, J. (2010). Natural antioxidants: fascinating or mythical biomolecules?. Molecules, 15(10), 6905-6930.
[15] Bouaziz, M., Feki, I., Ayadi, M., Jemai, H., \& Sayadi, S. (2010). Stability of refined olive oil and olive-pomace oil added by phenolic compounds from olive leaves. European Journal of Lipid Science and Technology, 112(8), 894-905.

[16] Neo Y,P, Ariffin A, Tan C..P,, and Tan, Y.A. (2010). Phenolic acid analysis and antioxidant activity assessment of oil palm (E. guineensis) fruit extracts. Food Chem.Vol. 122(1):353-9.

[17] De Souza A., L.A., M.L.M. Carvalho, C.A.G. Crislaine Aparecida Gomes Pinto, V.Y. Kataoka and T.T.A. Silva, ( 2013). Deterioration of sunflower seeds during storage. Journal of Seed Science, 35(2): 240-247.

[18] Moreal,R.A., Singh.v., Eckhoff.S.R., Powell.M.J., Hicks. K.B and Norton.R.A (1990). A comparison of yield and composition of oil exctracted from corn fiber and corn fiber bran.Cereal chemistry, 76: 449451.

[19] Lowell, B.K. (2006). The change in the peroxide values of corn and cottonseed oils under various storage conditions. J. Am. Oil. Chem. Soc. 10(4): 66-68.

[20] Nwobi BE, Ofoegbu O, Adesina OB (2006). Extraction and Qualitative Assessment of African Sweet Orange Seed Oil. Afr. J. Food Agric. Nutr. Dev. 6(2).

[21] Orthoefer.F.T, Sinram.R.D. eds Waston S,A. and Ramstad P.E.,(1987). corn oil: composition, processing and ultilization, in corn, chemistry and technology American Association of cereals chemists, St Paul, MU, 535-552.

[22] Elmastas, M.; Cinkilic, S. and Aboul - Enein, H. Y.(2015). Antioxidant Capacity and Determination of Total Phenolic Compounds in Daisy (Matricaria Chamomilla, Fam. Asteraceae). World J. of Analytical Chemistry, 3: 9-14.

[23] Moussawi, Umm al-Humad Humaid Jaber and Al-Halafi, Sawsan Ali Hamid (2012). The use of some plant extracts as microbial inhibitors and natural oxidants. Basrah Agricultural Sciences .25 (Special No. 3) .826-835.

[24] Slinkard, K. and Singleton, V. L. (1997). Total phenol analyses: Automation and caparison with manual methods. American. J. Enology and viticulture, (28):49-55.

[25] Huang,D.;Lin,C.;Chen,H.and Lin,Y.H.(2004).Antioxidant and antiproliferative activities ofsweet potato (Ipomoea batata L.) Lam(Tainong 57) constituents. Bot .Bull.Acad.Sin. 45: 179-186.

[26] Moussawi, Umm al-Humad Humaid Jaber and Al-Halafi, Sawsan Ali Hamid (2012). The use of some plant extracts as microbial inhibitors and natural oxidants. Basrah Agricultural Sciences .25 (Spe- 
cial No. 3) .826-835.

[27] Osawa, T. and Namiki, M. (1981). Anovel type of antioxidants isolated from leaf wax of Eucalyptus leaves. Agri. Biol. Chem, 45: 735-739.

[28] Scott, G. (1965). Atmospheric oxidation and antioxidant. Elsevier Publishing. New York.

[29] Assocaition of Official Analaytical Chemists A.O.A.C. (2008). Official Methods of Analysis 16thed. Assocaition of Official Analaytical Chemists International Arligton, Virginia, U.S.A.

[30] Cai, Y., Z.; Luo, Q.; Sun, M. and Corke, H. (2004). Antioxidant activity and phenolic compounds of 112 traditional Chinese medicinal plants associated with anticancer. Life Sci., 74: 2157-2184.

[31] Tawaha, K., Alali, F.Q., Gharaibeh, M., Mohammad, M.and El-Elimat, T. (2007). Antioxidant activity and total phenolic content of selected Jordanian plant species. Food Chemistry 104: 1372-1378.

[32] Nickavar, B. and Abolhsani, F. A. (2009). Screening of Antioxidant properties of seven umbellferae fruits from Iran. Pak. J. pharm. Sci., 22: 30-35.

[33] Al-Mudhafr ,A.W.H, ; Shaymaa M. AL-Selawi, and Hameed. A. H. Al-Hjar (2019) Study the Effect of Phenolic Compounds Extracted From Carrot Plant and Assess Their Effectiveness as Antioxidant Plant Archives , 19 (2), 864 - 868.

[34] Kähkönen, M.P.; Hopia, A.I.; Vuorela, H.J.; Rauha, J.P.; Pihlaja, K.;Kujala, T.S and Heinonen, M. (1999). Antioxidant activity of plant extracts containing phenolic compounds . J. Agric. Food Chem. , Vol.47, No.10,pp. 3954-3962.

[35] Erminda T., Maria A., Keysson V.F., Denise M. G. Freire, A. M. and Apostolis A. K. (2019) Extraction of Phenolic Compounds from Palm Oil Processing Residues and Their Application as Antioxidants, Food Technology and Biotechnology Vol. 57(1) pp:121.

[36] Roiaini, M., Ardiannie, T., \& Norhayati, H. (2015). Physicochemical properties of canola oil, olive oil and palm oil blends. International Food Research Journal, 22(3).

[37] Al-Mudhafr, A.W.H. (2019) Studying the properties of the active compounds extracted from the seeds of some root plants and the effect of preserving sun flower oil, Journal of Food and Nutrition Research 7 (8), 573-578.

[38] Genstat,( 2009) General Statistical Genstat Guides Vol. 12 Copyright 2009, VSV ,international Ltd.UK . 